2

I N S N

\title{
Komunitas SEHATI (Sehat Jiwa dan Hati) Sebagai Intervensi Kesehatan Mental Berbasis Masyarakat
}

\author{
YUDI KURNIAWAN ${ }^{*}$ \& INDAHRIA SULISTYARINI ${ }^{2}$ \\ [1] Fakultas Psikologi, Universitas Semarang \\ [2] Fakultas Psikologi dan Ilmu Sosial Budaya, Universitas Islam Indonesia
}

\begin{abstract}
ABSTRAK
World Federation of Mental Health (WFMH) sebagai bagian dari World Health Organization (WHO) menyatakan bahwa masalah kesehatan mental tidak lagi dilihat secara individual, namun harus diintervensi dalam skala makro/sistem. Oleh karena itu, pengetahuan praktis mengenai kesehatan mental selayaknya juga dipahami oleh masyarakat. Partisipan dalam penelitian aksi ini adalah masyarakat Pedukuhan X di Kecamatan Moyudan, Sleman, D.I. Yogyakarta. Tujuan penelitian aksi ini adalah membentuk komunitas masyarakat sehat jiwa dan hati (SEHATI) yang bisa mendeteksi gejala awal masalah kejiwaan dan dapat segera melaporkannya kepada profesional kesehatan mental di Puskesmas. Metode penelitian yang dilakukan adalah penelitian tindakan dengan melibatkan keluarga pasien dan perangkat pedukuhan (tokoh masyarakat dan pengelola pendidikan). Intervensi dilakukan dengan teknik psikoedukasi yang dibagi dalam tiga materi untuk tiga kelompok berbeda. Hasil utama Penelitian aksi ini adalah pembentukan kader kesehatan mental yang bertugas membantu profesional kesehatan mental di Puskesmas. Oleh karena itu, perlu diadakan pelatihan rutin untuk meningkatkan kemampuan kader kesehatan mental.
\end{abstract}

Kata kunci: kader sehat jiwa, kesehatan mental, komunitas.

\begin{abstract}
World Federation of Mental Health (WFMH) as part of the World Health Organization (WHO) stated that mental health problems are no longer viewed individually, but should be solved at a macro scale. Therefore, the practical knowledge of mental health should also be understood by the public. Participants in the study were community members of Pedukuhan Moyudan X in the District Moyudan, Sleman, Special Region of Yogyakarta. The research objective was to establish a community of sehat jiwa dan hati (SEHATI), which could detect the early symptoms of psychiatric problems and could immediately report it to a mental health professional at the healthcare facilities. The research method was action research involving the patient's family and the village organizers (community leaders and managers of education). The intervention was performed using psychoeducation and was divided into three materials for three different groups. The main result of this action research was the establishment of mental health cadres in charge of helping mental health professionals at the health center. Therefore, there should be regular training to improve mental health cadres.
\end{abstract}

Key words: community, mental health, mental health cadres. 
INSAN Jurnal Psikologi dan Kesehatan Mental, 2016, Vol. 1(2), 112-124, doi: 10.20473/JPKM.v1i22016.112-124 Dikirimkan: 25/11/2016 Diterima: 09/12/2016 Diterbitkan: 31/12/2016

Editor: Rizqy Amelia Zein

*Alamat korespondensi: Jalan Soekarno-Hatta, Semarang, Jawa Tengah 50196. Surel: kurniawan.yudika@gmail.com

Naskah ini merupakan naskah dengan akses terbuka dibawah ketentuan the Creative Common Attribution License (http://creativecommons.org/licenses/by/4.0), sehingga penggunaan, distribusi, reproduksi dalam media apapun atas artikel ini tidak dibatasi, selama sumber aslinya disitir dengan baik.

\section{PE N D A H U L U A N}

Tingginya kasus gangguan kejiwaan di seluruh dunia menjadi perhatian khusus para pemangku kepentingan yang terkait dengan kebijakan kesehatan mental. Pada tahun 2014, WHO menetapkan Living with Schizophrenia sebagai tema hari kesehatan mental sedunia yang diperingati tiap tanggal 12 Oktober. Tema ini dipilih karena Skizofrenia merupakan gangguan psikotik yang paling lazim terjadi dan memiliki prevalensi global cukup tinggi, yaitu 0.7-1\% dari total populasi seluruh dunia (World Federation of Mental Health (WFMH), 2014). Referensi lain menyebutkan rentang 0.5-2\% dari total populasi global sebagai prevalensi Skizofrenia di dunia (Davey, 2008).

WFMH sebagai bagian dari WHO, menyatakan bahwa kasus Skizofrenia tidak dapat lagi dilihat secara individual, namun harus diintervensi dalam skala makro/sistem. Skizofrenia, gangguan psikotik, dan gangguan neurotik umumnya terjadi karena tekanan yang berasal dari keluarga ataupun masyarakat. Oleh karena itu, pengetahuan praktis mengenai gangguan jiwa berat tersebut selayaknya juga dipahami oleh masyarakat.

Hasil Riset Kesehatan Dasar (Riskesdas) (Balai Penelitian dan Pengembangan Kesehatan, 2013) menunjukkan angka prevalensi gangguan jiwa berat di Indonesia 1.7 permil, artinya ada sekitar 1.7 kasus gangguan jiwa berat di antara 1000 orang penduduk Indonesia. Gangguan jiwa berat adalah gangguan jiwa yang ditandai dengan terganggunya kemampuan menilai realitas dan tilikan diri (insight) yang buruk. Gejala yang menyertai gangguan ini antara lain berupa halusinasi, wahan, gangguan proses pikir dan kemampuan berpikir, dan tingkah laku aneh seperti katatonik. Skizofrenia dan gangguan psikotik adalah contoh dari gangguan jiwa berat yang lazim terjadi di masyarakat. Orang yang mengalami gejala psikotik disebut dengan Orang Dengan Gangguan Jiwa (ODGJ).

Prevalensi gangguan jiwa berat tertinggi terdapat di Daerah Istimewa Yogyakarta (DIY) dan Aceh, dengan angka 2.7 kasus per 1000 penduduk. Angka ini bahkan lebih tinggi 1 permil daripada prevalensi kasus gangguan jiwa berat nasional. Ada banyak faktor yang menyebabkan tingginya kasus gangguan jiwa berat di kedua provinsi tersebut. Untuk Aceh, kasus gangguan jiwa mayoritas disebabkan oleh trauma pasca bencana dan trauma pasca konflik bersenjata. Sementara untuk DIY mayoritas gangguan jiwa berat disebabkan oleh faktor kesulitan ekonomi (Balai Penelitian dan Pengembangan Kesehatan, 2013).

Pada kategori gangguan mental emosional penduduk berusia di atas 15 tahun, DIY berada pada peringkat ketiga setelah Sulawesi Tengah (11.6\%) dan Sulawesi Selatan serta Jawa Barat (9.3\%), dengan prevalensi kasus 8.1\%. Gangguan mental emosional adalah kondisi yang mengindikasikan perubahan psikologis pada seseorang. Gangguan mental emosional dapat dialami oleh semua orang pada kondisi distres psikologis, namun tetap dapat pulih seperti semula. Individu yang mengalami masalah mental emosional disebut Orang Dengan Masalah Kejiwaan (ODMK). Apabila tidak 
mendapatkan intervensi dari profesional kesehatan mental, orang dengan gangguan mental emosional dapat mengalami gangguan yang lebih serius.

Hasil Riskesdas 2013 sejalan dengan situasi yang ditemukan oleh Pedukuhan X di Puskesmas Moyudan, Kabupaten Sleman, Provinsi DIY. Dalam rentang September-Desember 2014, rata-rata pasien yang dirujuk ke psikolog setiap harinya berjumlah 3-4 orang. Jumlah ini di luar konsultasi calon pengantin. Dalam sebulan, sedikitnya psikolog menangani 90-100 pasien. Dari jumlah tersebut, 1-2 persen adalah pasien gangguan jiwa berat yang rawat jalan setelah keluar dari rumah sakit jiwa. Sisanya adalah pasien dengan keluhan stres, gejala depresi, dan gejala somatofom. Data tersebut diperoleh oleh peneliti berdasarkan observasi dan wawancara terhadap psikolog dan perawat jiwa di Puskesmas Moyudan.

Berdasarkan data yang dikumpulkan oleh psikolog dan perawat jiwa pada tahun 2014, kategori gangguan jiwa berat di Kecamatan Moyudan mencapai 172 kasus. Sebanyak 47 orang dari seluruh kasus tersebut pernah rawat jalan baik di puskesmas maupun rumah sakit jiwa. Data tersebut dikumpulkan dengan metode observasi berdasarkan gejala dan wawancara terhadap keluarga. Beberapa indikator yang digunakan adalah tilikan diri yang buruk, kurangnya perawatan diri, menarik diri dari lingkungan sosial, berbicara dan tertawa sendiri, serta sering pergi tanpa tujuan jelas. Menurut petugas Kecamatan, penduduk Moyudan pada sensus tahun 2013 berjumlah sekitar 34 ribu jiwa, sehingga prevalensi kasus gangguan jiwa berat di Moyudan sekitar 0,5 kasus per 100 penduduk. Kelurahan yang memiliki kasus gangguan jiwa berat tertinggi adalah Sumber Agung dengan 51 kasus. Sekitar 17 persen kasus berasal dari Pedukuhan X (9 pasien gangguan jiwa berat). Seluruh data tersebut diperoleh oleh peneliti dari psikolog dan perawat jiwa di Puskesmas Moyudan.

Undang-Undang Nomor 18 tahun 2014 tentang Kesehatan Jiwa dalam pasal 1 ayat 4 menyebutkan bahwa upaya kesehatan jiwa adalah setiap kegiatan untuk mewujudkan derajat kesehatan jiwa yang optimal bagi setiap individu, keluarga, dan masyarakat dengan pendekatan promotif, preventif, kuratif, dan rehabilitatif yang diselenggarakan secara menyeluruh, terpadu, dan berkesinambungan oleh Pemerintah, Pemerintah Daerah, dan/atau masyarakat. Menurut amanat undang-undang, penatalaksanaan masalah kejiwaan tidak hanya menjadi tugas pemerintah, namun juga ada peran masyarakat di dalamnya. Pada kenyataannya, di Pedukuhan X belum ada semacam petugas atau kader yang dapat terlibat dalam aktivitas promotif/preventif masalah kejiwaan.

Berdasarkan kesenjangan situasi tersebut, Pedukuhan X tertarik untuk membuat konsep pedukuhan sehat jiwa berbasis komunitas/masyarakat. Jika terwujud, gagasan ini akan menjadi proyek percontohan untuk diterapkan dalam skala komunitas yang lebih besar. Berdasarkan asesmen awal terhadap kepala dukuh X, Pedukuhan X memperoleh informasi bahwa banyak kasus gangguan jiwa yang terjadi di dalam satu keluarga. Usia penderita gangguan jiwa berada dalam rentang 18-35 tahun. Pedukuhan X juga melakukan wawancara terhadap ibu yang memiliki dua anak dengan gangguan jiwa berat. Salah satu faktor utama pemicu gangguan jiwa adalah masalah sosial ekonomi seperti pengangguran. Mayoritas masyarakat Pedukuhan X bekerja sebagai buruh tani, sementara para pemuda biasanya merantau ke kota terdekat, seperti Wates atau Yogyakarta. Mereka yang mengalami gangguan jiwa umumnya menghadapi kegagalan saat bekerja di kota dan pulang tanpa membawa hasil. Minimnya pengetahuan masyarakat terhadap gangguan kejiwaan turut berpengaruh terhadap tingginya kasus gangguan mental di Pedukuhan X.

Target yang ingin dicapai oleh program ini adalah menciptakan masyarakat X yang pekan terhadap isu kesehatan jiwa sekaligus menghilangkan stigma negatif pasien gangguan jiwa di masyarakat. Program ini diharapkan dapat memberikan efek domino terhadap kualitas hidup pasien gangguan jiwa dan membantu pasien untuk beradaptasi kembali dengan lingkungannya. Konsep Pedukuhan sehat jiwa ini sekaligus menjadi komunitas yang positif untuk sarana promotif dan preventif kesehatan mental.

INSAN Jurnal Psikologi dan Kesehatan Mental

2016, Vol. 1(2), 112-124

doi: 10.20473/JPKM.v1i22016.112-124 
Wacana mengenai desa sehat jiwa sebenarnya telah lama muncul di puskesmas Moyudan. Hanya saja, pelaksanaannya terkendali pergantian psikolog yang cukup sering terjadi, sehingga keberlanjutan sebuah program juga tertunda. Oleh karena itu, psikolog yang bertugas saat ini di puskesmas Moyudan sangat antusias terhadap program pedukuhan sehat jiwa. Program ini nantinya akan diterapkan juga dalam skala desa dan kecamatan. Herrman \& Llopis (2005) menyebutkan bahwa promosi kesehatan mental adalah bagian dari hak publik untuk mendapatkan informasi kesehatan. Berkaca dari kasus di pedukuhan $\mathrm{X}$, masyarakat di sana berhak untuk mendapatkan informasi deteksi dini sebagai bentuk promotif dan preventif kesehatan jiwa, serta pendataan ulang warga dengan gangguan jiwa sebagai tindakan kuratif.

Penelitian ini bertujuan untuk memberikan psikoedukasi kepada masyarakat yang akan menjadi kader sehat jiwa terkait deteksi dini dan penanganan gangguan jiwa serta memberikan psikoedukasi kepada pengambil kebijakan setempat untuk merumuskan kebijakan yang pro kesehatan jiwa. Pelibatan unsur masyarakat sebagai kader sehat jiwa bertujuan agar mereka dapat menerapkan pengetahuan tersebut dan meneruskannya kepada anggota masyarkat lainnya.

\section{E T O D E}

\section{Prosedur}

Penelitian ini menggunakan pendekatan penelitian tindakan (action research) yang melibatkan subjek yang diteliti dan mereka diharapkan dapat meneruskan pengetahuan dari Pedukuhan X kepada anggota masyarakat lainnya dalam bentuk tindakan nyata. Penelitian tindakan menggunakan pendekatan kualitatif dan kuantitatif dalam proses asesmen dan analisis data. Variabel yang diukur dalam penelitian ini adalah informasi tentang kesehatan jiwa, yang meliputi materi deteksi dini masalah kejiwaan, penanganan masalah kejiwaan, dan kebijakan tentang masalah kejiwaan. Subjek yang terlibat dalam Penelitian aksi ini adalah masyarakat Pedukuhan X yang terbagi dalam tiga unsur, yaitu keluarga pasien psikotik, para ibu pengajar PAUD/PKK, para pengambil kebijakan. Sebelum pembentukan kader SEHATI, subjek Penelitian diberikan psikoedukasi terkait masalah kejiwaan dan tata laksanan penanganannya. Perubahan pengetahuan subjek diukur dengan menggunakan kuesioner pra dan pascapsikoedukasi. Data kuantitatif dianalisis dengan menggunakan paired sample t-test, sementara data kualitatif dianalisis dengan mengelompokkan hasil observasi dan wawancara pemangku kepentingan Pedukuhan X dalam tabel analisis SWOT.

Tabel 1. Alur Metode Penelitian Aksi yang Meliputi Pendekatan Kuantitatif dan Kualitatif

\begin{tabular}{|c|c|c|c|c|c|c|}
\hline SUBJEK & \multicolumn{3}{|c|}{ Instrumen Kuantitatif } & \multicolumn{3}{|c|}{ Instrumen Kualitatif } \\
\hline $\begin{array}{l}\text { Kelompok } \\
\text { Keluarga } \\
\text { pasien } \\
\text { psikotik }\end{array}$ & $\begin{array}{l}\text { Pengukuran } \\
\text { Prapsikoedukasi }\end{array}$ & Psikoedukasi & $\begin{array}{l}\text { Pengukuran } \\
\text { Pascapsikoedukasi }\end{array}$ & Observasi & Wawancara & $\begin{array}{l}\text { Analisis } \\
\text { SWOT }\end{array}$ \\
\hline $\begin{array}{l}\text { Kelompok } \\
\text { Kader } \\
\text { PAUD/ PKK }\end{array}$ & $\begin{array}{l}\text { Pengukuran } \\
\text { Prapsikoedukasi }\end{array}$ & Psikoedukasi & $\begin{array}{l}\text { Pengukuran } \\
\text { Pascapsikoedukasi }\end{array}$ & Observasi & Wawancara & $\begin{array}{l}\text { Analisis } \\
\text { SWOT }\end{array}$ \\
\hline $\begin{array}{l}\text { Kelompok } \\
\text { Pengambil } \\
\text { Kebijakan } \\
\text { Pedukuhan }\end{array}$ & $\begin{array}{l}\text { Pengukuran } \\
\text { Prapsikoedukasi }\end{array}$ & Psikoedukasi & $\begin{array}{l}\text { Pengukuran } \\
\text { Pascapsikoedukasi }\end{array}$ & Observasi & Wawancara & $\begin{array}{l}\text { Analisis } \\
\text { SWOT }\end{array}$ \\
\hline
\end{tabular}


D’Aunno, dkk. (1984; Prawitasari, 2011) dan Heller (1986; Prawitasari, 2011) menekankan adanya siklus kegiatan dalam penelitian tindakan. Siklus tersebut dimulai dengan definisi masalah, penemuan fakta, penentuan tujuan, tindakan, dan evaluasi. Berdasarkan evaluasi mengenai tindakan yang telah dilakukan akan ditentukan definisi masalah baru lagi dan demikian seterusnya. Pelaksanaan siklus tersebut melibatkan masyarakat dan penemuan fakta akan banyak dilakukan dengan penelitian yang sifatnya kualitatif (Prawitasari, 2011).

\section{Pengumpulan data}

Data dikumpulkan dengan teknik wawancara individual terhadap representasi perangkat Pedukuhan dan focus group discussion (FGD) yang melibatkan Kepala Pedukuhan, pengurus PAUD, kader sehat jiwa dari Puskesmas, dan salah satu keluarga pasien Skizofrenia. Metode ini dipilih oleh Pedukuhan X karena dapat mencakup sekelompok orang dalam waktu relatif singkat.

\section{HAS IL PENELITIAN}

\section{Data Kualitatif}

Hasil observasi yang dilakukan Pedukuhan X pada kelompok masyarakat Pedukuhan X menunjukkan bahwa mayoritas penduduk Pedukuhan X bekerja sebagai buruh tani dan pedagang di pasar. Dari sisi pendidikan, mayoritas penduduk usia 40 tahun ke atas berpendidikan SMP, sementara penduduk usia 18-35 tahun sebagian besar berpendidikan akhir SMA. Beberapa warga juga ada yang melanjutkan pendidikan hingga jenjang pendidikan S1.

Beberapa kegiatan sosial yang rutin diadakan di Pedukuhan $\mathrm{X}$ adalah pos pelayanan terpadu (Posyandu) balita pada tanggal 25 tiap bulannya, pendidikan anak usia dini yang diadakan 2 kali dalam seminggu, pertemuan rutin tokoh masyarakat setiap satu bulan sekali, dan pengajian ibu-ibu yang juga diadakan sebulan sekali. Seluruh aktivitas masyarakat dilakukan di masjid pedukuhan atau pendopo rumah kepala dukuh.

Seluruh warga yang namanya tercatat sebagai pasien gangguan mental berasal dari keluarga dengan status ekonomi menengah ke bawah dan tidak memiliki pekerjaan tetap. Selain itu, beberapa pasien juga masih berkerabat dekat, bahkan ada pasien yang merupakan kakak beradik kandung. Salah satu hambatan pasien jiwa untuk mendapatkan pengobatan adalah sikap keluarga yang cenderung tertutup dan tidak ingin anggota keluarga mereka dibawa ke Puskesmas atau Rumah Sakit Jiwa (RSJ).

Hasil wawancara terhadap Kepala Dukuh X menunjukkan bahwa sejak dahulu memang telah ada masyarakat yang mengalami gangguan jiwa di pedukuhan X. Penyebabnya sebagian besar karena tekanan ekonomi dan masalah keluarga. Gejala yang umum ditunjukkan oleh penderita gangguan jiwa tersebut adalah berjalan tanpa tujuan, tidak menggunakan pakaian, dan berbicara sendiri. Meskipun tampak menerima, keluarga dengan anggota yang mengalami gangguan jiwa juga menjadi bahan perbincangan bagi penduduk warga lainnya. Hampir semua keluarga yang memiliki pasien jiwa bersikap tertutup dan tidak banyak berbaur dalam kegiatan masyarakat.

Tokoh perempuan di Pedukuhan X menyampaikan bahwa selama ini banyak ibu yang tidak paham bagaimana cara mendidik dan menangani perilaku anak dengan tepat. Menurutnya, situasi ini berpengaruh terhadap kondisi anak di masa dewasa, karena banyak keluarga dengan anggota keluarga yang mengalami gangguan jiwa punya masalah komunikasi. Pada saat pengajian, sebenarnya cukup banyak ibu yang mengeluhkan perilaku anaknya. Mereka tidak tahu harus berkonsultasi kepada siapa. Hanya segelintir keluarga pasien jiwa yang sering ikut pengajian. Sementara sianya jarang berbaur dalam kegiatan sosial masyarakat.

INSAN Jurnal Psikologi dan Kesehatan Mental

2016, Vol. 1(2), 112-124

doi: 10.20473/JPKM.v1i22016.112-124 
Kader Posyandu di Pedukuhan X menyampaikan bahwa sebenarnya beberapa waktu lalu sempat akan dilakukan pendataan mengenai pasien jiwa di Pedukuhan $\mathrm{X}$, namun terkendala dengan beberapa keluarga yang cenderung tertutup terhadap kondisi pasien jiwa sebenarnya. Menurut narasumber, dia bersyukur karena di Pedukuhan X tidak ada kasus pemasungan terhadap pasien jiwa. Namun kasus stigma negatif ataupun anggapan miring terkait kondisi pasien jiwa masih ada. Dia menduga keluarga sebenarnya merasa malu dengan kondisi pasien jiwa dan akhirnya merasa rendah diri saat harus berinteraksi dengan masyarakat lain. Narasumber menyarankan agar dilakukan pendekatan dari tokoh masyarakat untuk berdialog dengan keluarga yang memiliki pasien jiwa.

Salah satu keluarga pasien psikotik menyampaikan bahwa penyebab kedua anaknya mengalami gangguan kejiwaan karena pengangguran dan tidak memiliki pekerjaan. Anak laki-lakinya yang berusia 35 tahun sempat kuliah hingga semester 6 namun tidak diselesaikan. Putus kuliah dan pulang kampung dengan kondisi menganggur dianggap sebagai salah satu sebab dia mengalami gangguan kejiwaan. Sehari-harinya, kedua pasien psikotik itu lebih banyak diam di teras rumah atau berkeliling pedukuhan tanpa tujuan yang jelas. Selama ini belum ada petugas Puskesmas yang datang dan menanyakan kondisi kejiwaan anaknya. Keluarga pasien sebenarnya membutuhkan informasi mengenai penanganan pasien jiwa dan bagaimana cara untuk mendapatkan jaminan kesehatan, karena biaya obat yang cukup tinggi.

Tabel 2. Analisis Kualitatif SWOT Masyarakat Pedukuhan X

\begin{tabular}{|c|c|}
\hline $\begin{array}{l}\text { Analisis SWOT } \\
\text { Strength }\end{array}$ & Keterangan \\
\hline \multirow[t]{6}{*}{ Strength } & a. Pasien Jiwa \\
\hline & $\begin{array}{l}\text { 1. Cukup kooperatif saat ada orang lain yang berkunjung ke rumahnya, tidak } \\
\text { agresif. }\end{array}$ \\
\hline & b. Keluarga Pasien \\
\hline & $\begin{array}{l}\text { 1. Punya keinginan agar pasien jiwa bisa mendapatkan penanganan yang lebih } \\
\text { baik. }\end{array}$ \\
\hline & c. Masyarakat Sekitar \\
\hline & $\begin{array}{l}\text { 1. Relasi masyarakat yang cukup guyub yang ditandai dengan banyaknya kegiatan } \\
\text { masyarakat. Kondisi ini dapat memudahkan proses sosialisasi tentang kesehatan } \\
\text { jiwa. }\end{array}$ \\
\hline
\end{tabular}

Weakness a. Pasien Jiwa

1. Jarak antara onset gangguan jiwa dan proses intervensi cukup jauh

b. Keluarga Pasien

1. Beberapa keluarga pasien tidak ingin kondisi anggotanya yang memiliki gangguan jiwa diketahui oleh masyarakat.

c. Masyarakat Sekitar

1. Adanya selentingan/kabar yang berkembang menjadi prasangka tentang masyarakat yang memberikan stigma negatif pada keluarga dan pasien jiwa.

Opportunity

a. Pasien Jiwa

1. Adanya keinginan dari keluarga untuk memberikan pengobatan yang lebih baik bagi pasien jiwa.

b. Keluarga Pasien

1. Adanya keinginan dari pemangku kepentingan di pedukuhan untuk memberikan edukasi mengenai kesehatan jiwa

c. Masyarakat Sekitar

1. Adanya peluang yang diberikan pihak puskesmas dengan membentuk komunitas pedukuhan sehat jiwa.

Threat a. Keluarga Pasien

1. Stigma negatif yang bisa menjadi penghambat keinginan keluarga untuk mendapatkan pelayanan kesehatan jiwa yang lebih baik lagi.

2. Bebera keluarga terbuka dengan pendataan kondisi pasien jiwa.

b. Masyarakat Sekitar

INSAN Jurnal Psikologi dan Kesehatan Mental

2016, Vol. 1(2), 112-124

doi: 10.20473/JPKM.v1i22016.112-124 
1. Program puskesmas tentang kesehatan jiwa yang bisa saja sewaktu-waktu dihentikan.

Tabel 3. Pelaksaan Psikoedukasi pada Subjek Ibu dan Keluarga Pasien Psikotik

\begin{tabular}{ll}
\hline Hari, Tanggal & Jumat, 10 Oktober 2014 \\
\hline Waktu & $15.30-17.30$ WIB \\
Masaran & Para ibu dan keluarga pasien jiwa pedukuhan Pedukuhan X \\
Materi & Pola Asuh Orang Tua dan Dampaknya terhadap Kesehatan Jiwa Anak \\
Target yang ingin dicapai & $\begin{array}{l}\text { 1. Peserta dapat memahami aspek emosi anak usia dini } \\
\text { 2. Peserta dapat memahami pola asuh ideal yang berpengaruh positif } \\
\text { terhadap perkembangan emosi anak }\end{array}$ \\
& $\begin{array}{l}\text { 3. Peserta dapat memahami peran orang tua sebagai pemantau } \\
\text { perkembangan psikologis anak }\end{array}$ \\
& $\begin{array}{l}\text { 4. Peserta dapat memahami aspek deteksi dini gangguan emosi pada } \\
\text { anak dan remaja }\end{array}$
\end{tabular}

\section{Hasil Intervensi}

1. Peserta memahami aspek emosi anak usia dini

2. Peserta memahami pola asuh ideal yang berpengaruh positif terhadap perkembangan emosi anak

3. Peserta memahami peran orang tua sebagai pemantau perkembangan psikologis anak

4. Peserta memahami aspek deteksi dini gangguan emosi pada anak dan remaja

Tabel 4. Pelaksaan Psikoedukasi pada Subjek Tokoh Masyarakat Pedukuhan X

\begin{tabular}{ll}
\hline Hari, Tanggal & Minggu, 9 November 2014 \\
\hline Waktu & $20.00-21.30$ WIB \\
Sasaran & Para bapak dan tokoh masyarakat pedukuhan Pedukuhan X \\
Materi & Peran Masyarakat dalam Pencegahan dan Penanganan Gangguan \\
& Kejiwaan \\
Target yang ingin dicapai & 1. Peserta dapat mengetahui aspek kesehatan jiwa \\
& 2. Peserta dapat mengetahui jenis gangguan jiwa yang lazim terjadi \\
& di masyarakat \\
& 3. Peserta dapat mengetahui penyebab gangguan kejiwaan \\
& (. Peserta dapat mengetahui apa saja langkah untuk mencegah \\
& gangguan kejiwaan
\end{tabular}

\section{Hasil Intervensi}

1. Peserta mengetahui aspek kesehatan jiwa

2. Peserta mengetahui jenis gangguan jiwa yang lazim terjadi di masyarakat

3. Peserta mengetahui penyebab gangguan kejiwaan

4. Peserta mengetahui apa saja langkah untuk mencegah gangguan kejiwaan

Tabel 5. Pelaksaan Psikoedukasi pada Subjek Masyarakat Desa Sumber Agung

\begin{tabular}{ll}
\hline Hari, Tanggal & Kamis, 20 November 2014 \\
\hline Waktu & $09.00-12.00$ WIB \\
Sasaran & Kader Kesehatan Jiwa Desa Sumber Agung, Moyudan \\
Materi & Peran Masyarakat dalam Pencegahan dan Penanganan Gangguan \\
& Kejiwaan \\
Target yang ingin dicapai & 1. Peserta dapat mengetahui aspek kesehatan jiwa \\
& 2. Peserta dapat mengetahui jenis gangguan jiwa yang lazim terjadi \\
\hline
\end{tabular}

INSAN Jurnal Psikologi dan Kesehatan Mental

2016, Vol. 1(2), 112-124

doi: 10.20473/JPKM.v1i22016.112-124

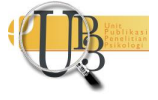


di masyarakat

3. Peserta dapat mengetahui penyebab gangguan kejiwaan

4. Peserta dapat mengetahui apa saja langkah untuk mencegah gangguan kejiwaan

Hasil Intervensi

5. Peserta dapat menjadi kader kesehatan jiwa di lingkungannya

1. Peserta mengetahui aspek kesehatan jiwa

2. Peserta mengetahui jenis gangguan jiwa yang lazim terjadi di masyarakat

3. Peserta mengetahui penyebab gangguan kejiwaan

4. Peserta mengetahui apa saja langkah untuk mencegah gangguan kejiwaan

5. Peserta menjadi kader kesehatan jiwa di lingkungannya

Tabel 6. Pelaksaan Tindak Lanjut Penelitian pada Subjek Kader Sehat Jiwa

\begin{tabular}{ll}
\hline Hari, Tanggal & Rabu, 4 Februari 2015 \\
\hline Waktu & $09.00-11.30$ WIB \\
Sasaran & Para kader kesehatan jiwa se-kecamatan Moyudan \\
Materi & Penyampaian hasil deteksi dini kesehatan jiwa di tiap pedukuhan \\
Target yang ingin dicapai & $\begin{array}{l}\text { 1. Kader dapat melakukan deteksi dini kesehatan jiwa pada } \\
\text { masyarakat di lingkungan sekitarnya. }\end{array}$ \\
& $\begin{array}{l}\text { 2. Kader melaporkan hasil temuannya kepada psikolog dan perawat } \\
\text { jiwa puskesmas }\end{array}$ \\
$\begin{array}{l}\text { Hasil Tindak Lanjut } \\
\text { Komunitas SEHATI telah berjalan dengan program pendataan pasien jiwa dan membahas hasil temuan di } \\
\text { puskesmas }\end{array}$
\end{tabular}

\section{Data Kuantitatif}

\section{Analisis Statistik Uji Beda untuk Psikoedukasi I}

Hasil analisis statistik uji beda dengan menggunakan paired sample t-test (uji beda skala pre dan post test pada kelompok yang sama dengan 15 peserta) menunjukkan ada perbedaan penyerapan informasi sebelum dan sesudah pemberian psikoedukasi, dengan nilai $\mathrm{p}=.000$ dan nilai $\mathrm{t}=-7.122$. Nilai rerata sebelum pemberian psikoedukasi adalah 8.93, sementara nilai rerata setelah pemberian psikoedukasi adalah 12.13.

\section{Analisis Statistik Uji Beda untuk Psikoedukasi II}

Hasil analisis statistik uji beda dengan menggunakan paired sample t-test (uji beda skala pre dan post test pada kelompok yang sama dengan 15 peserta) menunjukkan ada perbedaan penyerapan informasi sebelum dan sesudah pemberian psikoedukasi, dengan nilai $\mathrm{p}=.000$ dan nilai $\mathrm{t}=-9.242$. Nilai rerata sebelum pemberian psikoedukasi adalah 5.93, sementara nilai rerata setelah pemberian psikoedukasi adalah 10.33 .

\section{Analisis Statistik Uji Beda untuk Psikoedukasi III}

Hasil analisis statistik uji beda dengan menggunakan paired sample t-test (uji beda skala pre dan post test pada kelompok yang sama dengan 15 peserta) menunjukkan ada perbedaan penyerapan informasi sebelum dan sesudah pemberian psikoedukasi, dengan nilai $\mathrm{p}=.000$ dan nilai $\mathrm{t}=-9.471$. Nilai rerata sebelum pemberian psikoedukasi adalah 5.93, sementara nilai rerata setelah pemberian psikoedukasi adalah 11.20. 


\section{I S K U S I}

Keterlibatan masyarakat dalam mewujudkan komunitas sehat mental terbukti efektif membantu kinerja profesional di bidang kesehatan mental dan meningkatkan kesadaran kolektif terhadap pentingnya kesehatan mental. Menurut WHO (2001 dalam Herrman \& Llopis, 2005), kesehatan mental adalah kondisi psikologis di mana individu menyadari kemampuannya, mampu menghadapi stres dan menyelesaikan dengan cara positif, mampu bekerja produktif dan efisien, dan mampu memberikan kontribusi terhadap komunitas di mana dia bernaung. Penelitian ini menunjukkan bahwa kesehatan mental dapat ditingkatkan lewat pemberian psikoedukasi dan memberdayakan masyarakat untuk terlibat sebagai kader sehat jiwa.

Kesehatan mental adalah dasar bagi individu untuk berfungsi optimal sebagai seorang manusia dan menjalankan perannya di keluarga, lingkungan kerja, dan komunitas. Makna kesehatan mental telah diperluas dari sekadar tidak memiliki penyakit fisik kepada keberfungsian psikologis manusia dalam banyak spektrum kehidupannya. Kesehatan mental dimaknai kembali sebagai keseimbangan antara kesehatan fisik, sosial, budaya, psikologis, dan faktor personal lainnya seperti pemahaman terhadap diri sendiri.

Kasus di Pedukuhan X menunjukkan bahwa masalah gangguan kejiwaan mayoritas dialami oleh individu yang berasal dari kalangan ekonomi menengan ke bawah. Fakta tersebut dikonfirmasi oleh Desjarlais, dkk. (1995 dalam Herrman \& Llopis, 2005) bahwa masalah gangguan mental lazim terjadi pada masyarakat dari strata sosial menengah ke bawah. Masalah turunan yang disebabkan oleh kesehatan mental berakibat pada penderitaan, ketidakmampuan bekerja, hingga kematian. Topik mengenai kesehatan mental ini diabaikan oleh banyak pemangku kepentingan di berbagai negara, karena dianggap tidak secara langsung berdampak terhadap kesejahteraan warga. Padahal, justru kesehatan mental yang baik dan terjamin menjadi faktor penting yang mampu membuat masyarakat sejahtera.

Masalah kesehatan mental memang harus diintervensi dalam ranah komunitas/masyarakat. Studi yang dilakukan oleh Waddell, McEwan, Shepherd, Offord dan Hua (2005) di Kanada menunjukkan bahwa gangguan perilaku dan stres pada anak usia 7-14 tahun disebabkan oleh masalah di keluarga, sekolah, dan masyarakat. Jika tidak segera diintervensi, masalah perilaku pada anak akan berlanjut menjadi gangguan psikologis yang lebih berat di masa dewasa. Oleh karena itu, keluarga dan masyarakat perlu mendapatkan edukasi dan memahami deteksi dini gangguan mental, khususnya pada anak-anak.

Para tokoh di Pedukuhan X sebenarnya cukup paham bahwa masalah kesehatan mental tidak bisa diselesaikan sepihak. Perlu ada integrasi antara unsur keluarga pasien dan masyarakat. Selain itu, kesehatan mental perlu dipandang tidak hanya dari sudut penyakit atau gangguan mental. Ada istilah kesehatan mental positif yang artinya kondisi psikologis seseorang yang sehat mental dan memiliki penyesuaian dan kelenturan dalam menghadapi permasalahan hidup (Prawitasari, 2011). Orang yang sehat mental bukan berarti tidak pernah mengalami masalah, melainkan dia mampu kembali pada kondisi psikologis sebelum mengalami tekanan berat dalam hidupnya. Oleh karena itu muncul teori mengenai diatesis stres yang menyebutkan bahwa stres dan beban hidup yang ditanggung oleh manusia dalam hidupnya akan memengaruhi status kesehatan fisik dan mental individu. Konsep kesehatan mental positif ini juga disampaikan dalam materi psikoedukasi di Pedukuhan X.

Pada sesi psikoedukasi, subjek di Pedukuhan X diberikan pehaman bahwa gangguan jiwa berat ditandai oleh hilangnya kontak pasien dengan realita, muncul waham dan halusinasi, serta muncul perilaku yang tidak lazim. Gangguan jiwa berat yang banyak terjadi di masyarakat adalah adalah Skizofrenia. Skizofrenia juga didefinisikan sebagai kelompok gangguan psikotik yang ditandai dengan adanya gangguan pikiran, emosi dan tingkah laku, pikiran yang tidak terhubungkan, persepsi dan

INSAN Jurnal Psikologi dan Kesehatan Mental

2016, Vol. 1(2), 112-124

doi: 10.20473/JPKM.v1i22016.112-124

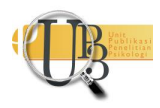


perhatian yang keliru, hambatan dalam aktivitas motorik, emosi yang datar dan tidak sesuai, dan kurangnya toleransi terhadap stres dalam hubungan interpersonal (Halgin, 2011). Saat pemaparan materi, banyak anggota keluarga pasien merasa terbantu dengan informasi yang diberikan oleh peneliti.

Gangguan Skizofrenia memiliki prevalensi sekitar 1 persen dari jumlah keseluruhan penduduk di muka bumi. Fakta ini menjadikan Skizofrenia sebagai gangguan psikotik dengan prevalensi tertinggi. Gejala skizorenia lazimnya muncul pada usia remaja akhir atau dewasa muda. Onset di atas usia 40 tahun sangat jarang terjadi. Sementara prognosis pada laki-laki cenderung lebih buruk daripada perempuan (Davey, 2008). Di Pedukuhan X, prevalensi kasus Skizofrenia sekitar 5 permil (5 kasus dari seribu penduduk).

Gejala-gejala Skizofrenia muncul dalam tiga fase yang dapat diprediksi (Furlow, 2000; Bonder, 2010). Fase pertama adalah prodromal, yaitu fase di mana beberapa fungsi sosial mulai mengalami penurunan. Individu mulai menarik diri dari linngkungan sosial. Selain itu kemampuan rawat diri juga mulai menurun. Tahap kedua disebut dengan fase aktif, yaitu fase di mana gejala positif psikotik seperti delusi dan halusinasi muncul. Fase ketiga adalah residual, dengan gejala yang menyerupai fase prodromal, namun dengan kualitas perilaku yang lebih buruk.

Skizofrenia pada umumnya ditandai oleh penyimpangan yang fundamental dan karakteristik dari pikiran dan persepsi, serta oleh afek yang tidak wajar (inappropriate) atau tumpul (blunted). Kesadaran yang jernih (clear consciousness) dan kemampuan intelektual biasanya terpelihara, walaupun kemunduran kognitif tertentu dapat dikembangkan kemudian. Skizofrenia merupakan label yang diberikan pada suatu kelompok psikosis, yang mengalami penurunan fungsi-fungsi yang ditandai dengan kekacauan fikiran, persepsi, suasana hati, tingkah laku yang aneh dan penghindaran sosial (Martin, dkk., 2007).

Individu dengan diagnosis Skizofrenia, umumnya diberikan pengobatan seperti obat-obatan, aktivitas program mengurangi gejala, mempromosikan atau melibatkan individu kedalam aktivitas dan interaksi sosial, sehingga mereka dapat membangun peran sosial atau keterampilan khusus di masyarakat (Mortensen, Pedersen \& Pedersen, 2010). Obat-obatan yang digunakan untuk mengobati Skizofrenia disebut dengan neuroleptics, yang artinya mengendalikan syaraf. Jika bekerja degan efektif, neuroleptics membantu penderita Skizofrenia untuk berpikir lebih jernih dan mengurangi gejala positif Skizofrenia. Obat-obatan tersebut bekerja dengan cara memengaruhi gejala positif (delusi, halusinasi, agitasi). Sementara dalam dosis yang lebih rendah, memengaruhi gejala-gejala negatif dan disorganisasi, seperti defisit sosial. Secara umum, setiap obat dapat efektif untuk sebagian orang dan tidak efektif bagi orang lainnya. Tim medis dan pasien seringkali harus menjalani proses trial dan error hingga menemukan komposisi obat yang paling efektif (Durand \& Barlow, 2007).

Salah satu efek buruk Skizofrenia adalah dampak negatifnya terhadap hubungan penderita dengan orang lain. Problem ini termasuk juga ke dalam materi yang disampaikan kepada masyarakat Pedukuhan X. Masalah ini dapat menjadi hambatan paling mencolok yang diperlihatkan oleh penderita Skizofrenia dan membuat mereka tidak mampu mempertahankan relasi sosial. Intervensi psikososial dapat digunakan untuk meningkatkan kepatuhan konsumsi obat dengan cara membantu pasien agar mampu mengkomunikasikan masalahnya kepada profesional (Durand \& Barlow, 2007).

Selain gangguan jiwa berat, masyarakat Pedukuhan $\mathrm{X}$ juga diberikan edukasi mengenai gangguan mental emosional. Gangguan mental emosional ditandai dengan menurunnya fungsi individu pada ranah keluarga, pekerjaan/pendidikan, dan komunitas/masyarakat. Gangguan ini berasal dari konflik alam bawah sadar yang menyebabkan kecemasan. Individu dengan gangguan mental emosional masih terkait dengan realita dan lingkungan sekitarnya, namun membutuhkan pertolongan/intervensi dari 
profesional bidang kesehatan jiwa. Beberapa jenis gangguan mental emosional yang lazim terjadi adalah depresi dan gangguan kecemasan.

Episode depresif adalah gangguan suasana perasaan (mood disorder) yang gejalanya meliputi ranah emosional, motivasi, perilaku, fisik, dan kognitif. Pengalaman emosional individu yang mengalami depresi biasanya terbatas pada emosi negatif yang sering dideskripsikan sebagai kesedihan, hilangnya harapan, kesengsaraan, dan hilangnya kegembiraan (Davey, 2008). Sebagian besar individu dengan gangguan depresi memiliki episode kesedihan dan perilaku menangis yang terjadi secara berkala. Hanya sebagian kecil saja individu dengan gangguan depresi yang dilaporkan pernah merasakan emosi positif. Individu dengan gangguan depresi menunjukkan wajah minim ekspresi positif dan kehilangan minat terhadap kesenangan/humor (Sloane, Strauss \& Wisner, 2001; Davey, 2008).

Individu dalam keadaan mood depresi memperlihatkan kehilangan energi dan minat, perasaan bersalah yang besar, sulit konsentrasi, perubahan perilaku makan yang signifikan, dan berpikiran untuk bunuh diri. Gejala lain adalah perubahan aktivitas, kognitif, verbal, ritme tidur, dan ritme biologis yang lain. Gangguan ini hampir selalu menghasilkan hendaya dalam hubungan interpersonal, sosial, dan fungsi pekerjaan (Ismail \& Siste, 2013). Beberapa anggota masyarakat menyadari bahwa selama ini mereka melihat gejala-gejala tersebut muncul pada beberapa individu di Pedukuhan X, namun mereka tidak pernah mengambil tindakan lebih lanjut.

Menurut Dobson dan Dozois (2008), timbulnya gangguan depresi dapat dipicu oleh faktor biologis, psikososial/faktor lingkungan, seperti peristiwa yang menimbulkan pengaruh emosi negatif mendalam. Pada individu yang mengalami episode depresi untuk pertama kali (memiliki gejala depresi dan terjadi selama minimal 2 minggu), ada tendensi untuk mengalami gangguan depresif berulang di masa yang akan datang. Ada korelasi yang kuat antara penyakit medis kronis dan peningkatan prevalensi gangguan depresi. Orang-orang dengan riwayat penyalahgunaan alkohol dan atau obat-obatan juga rentan mengalami gangguan depresi.

Warga Pedukuhan X mengalami perubahan kognitif dan perilaku setelah mendapatkan psikoedukasi tentang masalah kejiwaan. Sebagai sebuah komunitas, warga di Pedukuhan X mampu menciptakan rasa kebersamaan untuk menangani problem sosial di lingkungan mereka. Dalton, Elias dan Wandersman (2001) menyatakan komunitas sebagai wadah di mana ide muncul bersama di dalam beberapa kegiatan atau usaha bersama maupun hanya karena adanya kedekatan secara geografis. Hal ini sejalan dengan pernyataan dari Sarason (1974 dalam Dalton, dkk., 2001) bahwa komunitas adalah penyedia dengan mudah jaringan hubungan saling mendukung satu sama lain dan masing-masing individu memiliki ketergantungan di dalamnya. Dalton, dkk. (2001) menyatakan bahwa definisi dari sebuah komunitas merupakan defenisi yang diberikan oleh komunitas itu sendiri, sehingga setiap komunitas akan berbeda-beda dalam mendefenisikan komunitasnya.

Kloos, dkk. (2012) menyampaikan bahwa konsep psikologi komunitas berbeda dengan konsep psikologi lainnya, terutama psikologi individual, dalam dua aspek. Pertama, psikologi komunitas menawarkan kerangka berpikir yang berbeda mengenai konsep perilaku manusia, dengan melihat perilaku sebagai bagian dari dinamika sebuah komunitas. Aspek kedua adalah perluasan topik yang layak dipelajari dalam bidang psikologi.

Penelitian yang menggunakan pendekatan psikologi komunitas fokus untuk melihat cara yang efektif dalam mencegah gangguan mental alih alih mengobati setelah gangguan tersebut muncul. Konsekuensinya, fokus penelitian psikologi komunitas bukan pada dinamika psikologis individu, melainkan hubungan dalam keluarga dan masyarakat sebagai faktor yang mendukung atau menghambat perbaikan kesehatan mental. Hasil penelitian ini menegaskan bahwa intervensi kesehatan mental berbasis masyarakat efektif membantu petugas puskesmas untuk deteksi dini masalah kejiwaan, sekaligus menjadi wadah kegiatan promotif-preventif bagi warga.

INSAN Jurnal Psikologi dan Kesehatan Mental

2016, Vol. 1(2), 112-124

doi: 10.20473/JPKM.v1i22016.112-124 


\section{S I M P U L A N}

Penyebab utama gangguan kejiwaan di Pedukuhan $\mathrm{X}$ adalah tekanan sosial ekonomi dan tekanan sosial. Pola komunikasi dalam keluarga yang tidak cair menyebabkan anggota keluarga yang terkena masalah enggan berbagi cerita. Oleh karena itu, pembentukan komunitas pedukuhan sehat jiwa dan hati (SEHATI) dapat menjadi wadah promotif, preventif, dan kuratif terhadap masalah kesehatan jiwa di skala pedukuhan.

Setelah peneltian dilakukan, peneliti memberikan saran agar keluarga bisa menjalankan peran sebagai pelindung utama pasien jiwa dan mampu menciptakan kondisi emosi yang nyaman bagi mereka. Selain keluarga, peran masyarakat juga diharapkan untuk meneruskan perilaku bebas stigma negatif terhadap pasien jiwa kepada generasi berikutnya. Agar fungsi kader dalam komunitas pedukuhan SEHATI ini optimal, perlu adanya kerjasama antara Puskesmas dan perangkat pemerintahan hingga level kabupaten untuk merumuskan kebijakan terkait pencegahan dan penanganan kasus gangguan kejiwaan di masyarakat.

\section{PUSTAKA ACUAN}

Balai Penelitian dan Pengembangan Kesehatan. (2013). Riset Kesehatan Dasar. Jakarta: Kementerian Kesehatan Republik Indonesia.

Bonder, B. R. (2010). Psychopathology and Function $4^{\text {th }}$ Edition. New York: Slack Incorporated.

Dalton, J.H., Elias, M.J. \& Wandersman, A., (2001). Community Psychology. New Jersey: Wadsworth Thomson Learning.

Davey, Graham. (2008). Psychopathology: Research, Assessment, and Treatment in Clinical Psychology. Chicester: Blackwell Publishing.

Dobson, K. S. \& Dozois, D. J. A. (2008). Risk Factors in Depression. Amsterdam: Academic Press Publication.

Durand V. Mark \& David H. Barlow. (2007). Intisari Psikologi Abnormal. Terjemahan dari Essentials of Abnormal Psychology, Terj: Helly Prajitno Soetjipto dan Sri Mulyantini Soetjipto. Yogyakarta: Pustaka Pelajar.

Furlow, B. (2000). Radiologic Assessment Of Schizophrenia. Radiologic technology, 71(5), 463-463.

Halgin, W. (2011). Psikologi Abnormal Perspektif Klinis pada Gangguan Psikologis. Jakarta: Salemba Humanika.

Herrman, H., \& Jané-Llopis, E. (2005). Mental health promotion in public health. Global Health Promotion, 42.

Ismail, Irawati. R \& Kristiana Siste. (2013). Gangguan Depresi. Dalam Sylvia D. Elvira dan Gitayanti Hadikusumo (editor). Buku Ajar Psikiatri Edisi Kedua. Jakarta: Badan Penerbit Fakultas Kedokteran Universitas Indonesia.

Kloos, B., Hill, J., Thomas, E., Wandersman, A., \& Elias, M. J. (2012). Community psychology: Linking individuals and communities. Cengage Learning.

Martin, L. F., Hall, M. H., Ross, R. G., Zerbe, G., Freedman, R., \& Olincy, A. (2007). Physiology of schizophrenia, bipolar disorder, and schizoaffective disorder.American Journal of Psychiatry, 164(12), 1900-1906.

Mortensen, P. B., Pedersen, M. G., \& Pedersen, C. B. (2010). Psychiatric family history and schizophrenia risk in Denmark: which mental disorders are relevant?. Psychological medicine, 40(02), 201-210.

Prawitasari, J. E. (2011). Psikologi Klinis Pengantar Terapan Mikro dan Makro. Jakarta: Erlangga.

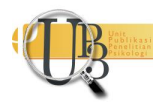


Waddell, C., McEwan, K., Shepherd, C. A., Offord, D. R., \& Hua, J. M. (2005). A public health strategy to improve the mental health of Canadian children. The Canadian Journal of Psychiatry, 50(4), 226233.

Sloan, D. M., Strauss, M. E., \& Wisner, K. L. (2001). Diminished response to pleasant stimuli by depressed women. Journal of abnormal psychology, 110(3), 488.

World Federation of Mental Health. (2014). World Mental Health Day. Diakses 27 Oktober 2016 dari http://wfmh.com/index.php/world-mental-health-day. 